Demography, Democracy and Disputes:

The Search for the Elusive Relationship Between Population Growth and International Conflict

Skyler J. Cranmer

Randolph M. Siverson

University of North Carolina, Chapel Hill University of California, Davis

November 16, 2007

For their helpful comments on earlier versions of this paper we thank Paul Diehl, Jefferson Gill, Lanny Martin, Richard Stoll, Jaroslav Tir, and James L. Ray. Particular thanks must be given to Colin Cameron, John Daniels, Cindy D. Kam and Michael D. Ward for their generous help. Replication data and code can be downloaded at http://www . unc. edu/ skyler. 


\begin{abstract}
We examine the propensity of states to initiate international conflict conditioned on four primary explanatory variables: (1) changes in population over varying lags, (2) democratic status of the state, (3) the power status of the state and (4) changes in the state's level of energy consumption. We hypothesize that the responsiveness of a government to the needs of its citizens is sufficiently important that the effect of population growth cannot be properly examined independently of democracy and that major powers tend to become involved in disputes for a much wider set of reasons than minor powers. Thus, we expect to find the strongest effect of population change on conflict initiation in democratic minor powers. We also expect that decreases in energy consumption concurrent with increases in population will lead to conflict initiation. A series of negative binomial regressions over 20 yearly time lags lends robust support to our expectations.
\end{abstract}


There is no shortage of research on the various consequences of population size and rates of population growth. These closely related subjects cover a broad spectrum of concerns, many of which relate to the problem of sustaining life without destroying the environment that supports it. A subsidiary concern in this literature has focused on the consequences of population growth for various political phenomena, including its possible contribution to the onset of international conflict. The basic question that motivates much of this research is, does an increase in a state's population increase the probability of its participation in international conflict?

That question is at the center of our inquiry. We approach it in the following manner. In the first section, we outline the basic empirical and theoretical literature on the relationship between population change and international conflict. In the second section we combine aspects of the previous research and insights into the nature of domestic political institutions to generate a set of expectations about the relationships we will uncover in the data. In the third section we present our data, research design and method of analysis. In the fourth section we present our analyses, using a series of graphs for the main results. In the final section we reflect on what has and has not been shown in the analysis.

\section{Population Growth and Conflict}

While there is empirical research on the question of population growth and international conflict, the results are mixed. After extensive empirical research Wright (1955), in an early study, concluded that "population pressures never create a necessity to go to war though they may create a necessity for action" (p. 363, emphasis added). Moreover, many subsequent studies have reported relationships that were either weak or nonexistent. As described by Krebs and Levy (2001): "Reviewing the literature of the last several decades, one is struck by how little progress has been made since Wright wrote on the subject over forty years ago." This is not for want of effort, but rather, as put by Tir and Diehl (1998), it is because of the "limited systematic research available on the subject." 
Tir and Diehl set out to rectify this. They approached the relationship of population growth and international conflict by applying a rigorous research design to a widely accepted data set that covered a large number of states over the period 1930-1989 (Tir and Diehl, 1998). Reasoning plausibly that the effects of population growth will not turn up immediately, Tir and Diehl use "the percentage rate of change across the ten years prior to the year under study." In their test they also employed a number of control variables, such as the state's military expenditures, energy consumption and its number of borders. Because the dependent variable was any militarized interstate dispute (MID) in which a state participated, they used logit analysis. They investigated a number of hypotheses, including the following: "The greater the growth of a state's population, the greater the probability of that state being involved in international militarized conflict" (Tir and Diehl, 1998, p.328). Note that this hypothesis does not center around evaluating any of the specific theories in which population growth is embedded. Their goal was simply to examine whether there is any reason to think that population growth itself is linked to international conflict.

Their results with respect to this hypothesis were straightforward showing a coefficient of .01 for population growth on dispute onset (with a standard error of .003 and a corresponding $p$ of .001). When they examined the marginal effect of this result, they reported that the average rate of population change over a ten-year period appeared to increase the probability of a state's participation in an international militarized dispute by about seven per cent. More importantly, after they partitioned the data into major and minor power states, they demonstrated that the observed effect was largely confined to the minor powers. ${ }^{1}$ Their explanation for this perhaps surprising result that the major powers did not show an effect for population pressures on dispute involvement was that because of the position they occupy in the international system these states have had many more opportunities to become involved in conflict than minor powers. Thus the effect of population growth, if any, may get lost in the "noise" of all the conflict involvement that derives from major powers doing what major powers typically do. 
In addition to exploring further the basic results of Tir and Diehl, we intend to add the theoretical perspective of earlier research by Choucri and North (1975). They hypothesized that the conflict behavior of states was powerfully shaped by changes in three master variables: population, resources and technology. In brief, as the population of a state increases, they anticipate corresponding increases in the material needs of this population and that these are supplied by the application of technology to resources. When population and technological growth outstrip the resources available, states will often look outside their borders to solve the problem, resulting in what Choucri and North term "lateral pressure." Some states will export population, but more frequently they turn to trade or the use of force to acquire what they need. While our brief description does not do justice to the full complexity of Choucri and North's treatment of the processes that can generate lateral pressure, it nonetheless conveys the central place in its logic for the idea that population growth, contingent on decreases in resource availability, may lead to conflict. Their research, first on World War I and the great powers and later on Japan in the period before World War II (Choucri, North, and Yamakage, 1992), traces out in detail the positive effects of population growth on the needs of the state that may have contributed to war.

Although Choucri and North have strikingly portrayed the effects of lateral pressure on the tensions that produced World War I, their conclusions are difficult to accept with full confidence, inasmuch as they are the result of a research design that contains selection bias. As noted by Tir and Diehl (1998, p. 326), the states whose behavior they observed were the states known ex post to have participated in World War I. Other states whose population may have changed since 1870, the beginning of their empirical domain, but that did not participate in the war's outbreak, such as, Spain, Sweden, the United States and Japan, were not included in the research design. Thus no matter how persuasive their theory or innovative their data analysis, since they selected on the dependent variable it becomes somewhat problematic to make a causal argument about the role of population change in the onset of international war. The cure for this is straightforward: the research design must be 
constructed in such a way that the cases include ex ante the full range of possible outcomes (Lieberson, 1985). Our analysis will do this.

Finally, in addition to the power status of states and their access to resources, it is worth considering the possibility that relationship between population growth and conflict behavior may be contingent upon the political institutions of the state. Despite the cottage industry that has developed around the idea that the political institutions of states powerfully affects their foreign policies, research on population growth and conflict has not, insofar as we are aware, differentiated the effects of population growth across different types of political systems. This is so in spite of the fact that there is more than ample reason to suspect that some types of political systems might be much less responsive than others in the provision of the resources needed by a growing population. It is, for example, a widely-held belief that democratic states are responsive to the wants of their populations. It is no less widely believed that non-democratic states are not similarly responsive and often ignore the needs of the broad population in favor of their narrower group of supporters (Wintrobe, 1998).

They can do this because institutional monarchies and autocracies are based upon small winning coalitions. Consequently, as argued by Bueno de Mesquita et al. (2003), the leaders of these states will be inclined to provide private goods for their cronies in the winning coalition rather than public goods for the larger population, whose political support is not necessary for remaining in power. This is even true when the selectorate (their term for the politically relevant part of the population from which the winning coalition emerges) is large but ineffectual because elections are rigged or choice is limited. Under this circumstance, leaders benefit from the "loyalty principle," under which those in the winning coalition can be bought off with less than when the selectorate is small, since they are aware that if they are excluded from the winning coalition, their chance of getting back in power is relatively small. In essence, the political system's structure makes it easier for the political elite to ignore or repress needs that might exist because of increasing population, and this may even include some members of the winning coalition. Democratic states, that is, those with large 
winning coalitions, have institutions that encourage leaders to provide for the welfare of large numbers of people. Leaders who do not do this expose themselves to an increased risk of removal (Bueno de Mesquita et al., pp. 273-326).

To be sure, we agree with Tir and Diehl's observation that minor powers will more sharply reveal the relationship between population increase and conflict, but here we also suggest the possibility that minor power democratic states with high rates of population growth will be more inclined to participate in militarized interstate disputes than democratic and non-democratic major powers and even non-democratic minor powers, particularly when the resources of the state are diminishing, as suggested by Choucri and North.

The expectations that follow from these sets of ideas are straightforward. First, following Tir and Diehl, we expect to find a larger effect of population growth on conflict initiation in that set of states known as minor powers than in the major powers. Second, as argued by Choucri and North, we expect that states experiencing resource shortfalls and population growth will be more likely to initiate conflict than those states which are not. Finally, a consideration of the political institutions of the state leads to the expectation that democratic states with a growing population will be more inclined to initiate conflicts than their authoritarian counterparts. A natural combination of these might lead to the expectation that conflict initiation will be more likely in democratic minor powers experiencing a resource shortfall than in other types of states. This may be the case, but it might also be that these three factors operate independently of each other.

\section{Research Design}

We use an extension and modification of the research design of Tir and Diehl on the relationship between population growth and international conflict. It is an extension of Tir and Diehl in five ways. First, our data span the time period 1816 to 1994, a considerably longer period than they covered. 
Second, we agree with their basic premise that population pressures will not have an immediate affect on the conflict behavior of states; it seems unreasonable to expect that any political system will respond to the gradual pressures of population change with consistent rapidity. Because we have little in the way of theoretical or empirical guidance, except for the results reported by Tier and Diehl for the ten-year lag, we analyze data on twenty lags, ranging from one year to twenty years.

Third, the data used by Tir and Diehl were effectively a pooled cross-sectional time series, but they were not treated as such, undoubtedly because the methods for this type of analysis were not well known when their research was reported. We take advantage of what is now known in the literature and available in statistical packages about analyzing panel data. Briefly, we capture random effects in the data by using a dummy variable for each year covered in the analysis. We account for effects that may exist within the panel for each state by clustering on the individual country codes.

A fourth difference between this research and that of Tir and Diehl is the nature and measurement of the dependent variable. The Militarized Interstate Dispute (MID) data set contains a number of disputes that involve only the threat of force. Indeed, many of these disputes are of such little import that the data do not record a response from the target. Does it make sense to think about these as being the dependent variable of interest? We think not, and so we center our attention on those disputes minimally involving the display of force, that is, MIDs at level 3, 4 and 5. In addition, as we explain below, to gain more information we use a count of the number of such disputes a state initiates in a year. We focus on initiation because when population growth creates, as Wright put it, the "necessity for action" states are likely not just to participate in disputes, but to be the initiator.

In addition, focusing on initiation enhances the independence of the cases in the data. That is, for every act of initiation in the data that minimally involves the display of force there is usually a response. Using dispute participation as the data of interest by including both the initiation and the response guarantees that the cases in the data set are not inde- 
pendent of each other. To be sure, we have not eliminated all sources of dependence, since initiating states may coordinate their policies, but focusing on initiation at least mitigates the difficulties of dependency in the data. ${ }^{2}$

There are several aspects of our research design that require brief comment, and we now provide details with respect to the states that constitute the data to be analyzed, the measurement of population growth, the nature of the lags, the measurement of democracy, and the form of the statistical analysis.

The states that constitute the basis of our study are those contained in the Correlates of War data. We identified them and obtained data on their total population in each year between 1816 and 1994 through the use of EUGene (Bennett and Stam, 2000). As mentioned above, a key covariate in the analysis is the percentage change in population over several lag lengths. This variable simply measures the percentage change in population growth over a number of years equal to the lag length used. We computed this quantity for all lag lengths from 1 to 20 .

The Choucri and North argument about population growth's affect on conflict hinges in part on resources that are either decreasing or not increasing as rapidly as population. As far as we are aware, there are no data that will allow us to tap resource levels across states for any lengthy period. As a surrogate for this we use the Correlates of War data on energy consumption, also derived from EUGene. We measure changes in energy consumption in the same manner as we measure changes in population. This variable was not without its complications, the most notable of which was that some parts of the data simply could not be trusted. For example, the series for Somalia reports energy consumption of 2 in 1967 that jumps to 943 in 1970. This pattern was evident in a number of states, particularly the newly independent African states in the late 1960s. ${ }^{3}$ We had the choice of dropping energy consumption from the analysis, extrapolating back the missing values, or dropping the suspicious cases. We chose the last of these. The first alternative would have vitiated an important part of the analysis. The second was appealing, but given the shortness of 
many of the individual series and the fact that the strings of untrustworthy data were not randomly distributed, we chose instead to drop the cases.

We created a dummy variable for democracy by subtracting a state's autocracy score from its democracy score. This resulted in a 21-point scale ranging from -10 to +10 , and those states with a resulting positive score of 4 or more were assigned a 1 . Those whose score was less than 4 were assigned a 0 . The missing data codes of $-66,-77$ or -88 were also given 0; those codes cover several circumstances, none of which can be remotely characterized as institutionally democratic. We created a dummy variable for the major powers, as given in Small and Singer (1982) and continued in EUGene, in which the major powers were assigned a 1 and all other states were given a 0 .

As we noted above, many recent studies of international conflict have used a dummy variable to indicate whether a dispute took place or not. Indeed, it may be seen as the standard approach to the measurement of international conflict. In a dyadic context, where disputes are relatively rare events, this probably makes sense; more than one dispute a year between two states in a particular dyad is likely be rare. However, in a monadic context this is not necessarily the case. For example, depending upon the lag in use, our data cover approximately 4877 to 7861 nation-years of data. The largest of these data sets contains 1,227 national dispute initiations with hostility levels of 3 or greater. These are tabulated in Table 1 . In these data, just over 15 per cent of the cases contain a dispute of interest to us. As compared to dyadic studies, where disputes may take place in about one per cent of the cases, what we see in the data are events that are not nearly as rare. In addition, as can be seen in Table 1, a not inconsequential number of the states participated in more than one dispute in a year. More precisely, of the total 1,227 disputes, 345(28 per cent) took place in the context of a state becoming involved in more than one dispute in a single year. This does not count the continuation of ongoing disputes. ${ }^{4}$

Count data of the kind displayed in Table 1 may be analyzed by the Poisson or negative binomial models. Because of considerable over-dispersion in the data we use the negative 
binomial on the dispute initiation counts and the Poisson on the far less dispersed territorial dispute initiations (Cameron and Trevedi, 1998).

\section{Table 1 about here}

To explore the effects of population growth on conflict initiation conditioned on types of political system and power status, we construct three variables. Initially, we construct indicator variables for minor power democracies (scored 1 when the state is both a democracy and a minor power and 0 otherwise), minor power non-democracies (scored 1 when the state is not democratic and is a minor power and 0 otherwise), and major power non-democracies (scored 1 when the state is both a major power and not democratic and 0 otherwise). We then form an interaction by multiplying these indicator variables by the individual state's rate of population growth across the individual yearly time lags. We do not construct a similar variable for major power democracies, as including it would saturate the model; the estimates for these states, however, can be seen in the coefficients for population growth itself.

To assess the effects of changes in energy consumption (drawn from the Correlates of War data), we then multiply these interactions by the changes in energy consumption. The full model, including all the main effects, is:

$$
\begin{aligned}
\text { Number.Initiations } & =\text { Pct.Population.Growth }+ \text { Democracy }+ \text { Major.Power } \\
& +(\text { Democratic.Minor } \times \text { Pop })+(\text { NonDemocratic.Major } \times \text { Pop }) \\
& +(\text { NonDemocratic.Minor } \times \text { Pop })+\text { Pct.Energy.Change } \\
& +(\text { Energy } \times \text { Pop.Growth })+(\text { Energy } \times \text { Dem.Minor.Pop }) \\
& +(\text { Energy } \times \text { NonDem.Major.Pop })+(\text { Energy } \times \text { NonDem.Minor.Pop })
\end{aligned}
$$

There are two other aspects of the analysis that merit mention. The first is the question of statistical significance. The data we use constitute a population of data rather than a sample; 
our dataset includes all recorded militarized interstate disputes between 1816 and 1994, not just a representative sample of them. As such, measures of significance such as p-values and confidence intervals cannot be interpreted in the same manner they would be if our data were a sample. While ours is not the only way to interpret confidence intervals in population data, we interpret them as measures of model fit rather than measures of uncertainty in an inference. Specifically, p-values and confidence intervals cannot reflect uncertainty about an inference in this setting because there is no uncertainty about the "trueness" of the trends in the data: the data are observed and all trends in them are factual. The confidence intervals we present reflect the degree to which our model fits the observed data; small confidence intervals indicate that our model fits the observed data quite well, larger confidence intervals indicate the model fits the data less well.

A second aspect of our research that requires explanation is that our results are presented in something close to a control variable free environment. The relative absence of the "usual suspects" of control variables is due to two reasons. First, we take control variables seriously. By this we mean that in our view they are included in models to assess the possibility that the observed relationship between the independent variable and the dependent variable is not due to their mutual relationship but instead to some other variable or variables. They should not be thoughtlessly included as "usual suspects." This is a controversial, indeed even contentious, position, as a number of recent papers demonstrate; but it is a position that we believe is soundly rooted in the basic elements of research design. ${ }^{5}$ Second, we are at a loss to propose a set of factors that could be related to both population growth over the various lags in our analysis and the number of violent MIDs in which a state participates. Can we plausibly draw a theoretical or empirical link between, for example, the number of a state's alliances or its involvement in intergovernmental organizations and both population growth and conflict initiation? We think this is doubtful. Should we include the size of the state's military forces? Initially this might seem appropriate, since states with a growing population will have the opportunity to increase the size of the military. However, it is hard to imagine 
that the size of the military generally leads to population growth (although members of the Baby Boomer generation will doubtless believe that demobilization does) and the size the military is probably better seen as an intervening variable that is not of compelling interest to us in the present research context.

\section{Results}

Because of the exceptionally large number of coefficients potentially of interest (i.e., 11 variables across 20 lags equals 220 coefficients), we display our main results in "rope ladder" plots of the coefficients and their confidence intervals for each of the independent variables across the time lags from 1 to 20. Using the graphs will have the advantage of facilitating the visual comparison of coefficients across lag lengths. Each of the graphs displays the point estimate, a vertical line representing its 95 per cent confidence interval, and, if zero falls between the lowest value of the lower confidence bounds and the highest value of the upper confidence bounds, a horizontal line representing it is included in the plot. However, because the graphs may not give the full expected informational value of the coefficients, the coefficients without zero in their confidence intervals will also be reported in tables.

Although we ran our analysis over 20 periods, the results we will display in the figures and tables will use only the lags for years three through 20, displayed lowest to highest across where the $x$-axis would be. We do this for two reasons. First, across almost all the analyses the coefficients for the first two lags had huge confidence intervals that invariably included zero. They were also widely at variance with the rest of the lags in the series. These were not informative beyond the fact that all the political systems seemed to need at last three years to begin to respond to the growth of population. Second, a consequence of the wide confidence intervals is that the scale of the figures was distorted and the results presented therein became difficult to discern, which, in turn, defeated the ease of visualization the graphs were supposed to impart. 
Figure 1 displays the results of the 20 analyses over the period 1816 to 1994 . Those coefficients having confidence intervals that do not include zero are also shown in Table 2. The coefficients for population growth, which capture the effect of population growth on dispute initiation for democratic major powers, the omitted category in the interactions, are essentially zero across all the lags. The coefficients for democracy are consistently negative and decreasing across time, while the coefficients for major power status are positive and increasing across time. The two sets of coefficients are not of particular interest to the research question at hand since they report their respective effects when population change is zero, and the nature of their relationship to conflict initiation might easily be predicted before any research was done.

Turning to the interaction of population change with the democracy and the power status indicator variables, the effect of population growth is clearly evident for the democratic minor powers. This appears in the third-year lag (0.73 as shown in Table 2) and runs with decreasing strength to the ninth-year lag (.28) with $95 \%$ confidence intervals that do not include zero. However, for the non democratic major and minor powers the confidence intervals for the coefficients all include zero.

\section{Figure 1 about here}

Positive results are also shown for the combined effects of population growth and decreases in energy consumption, but one set of these results is quite different from what we anticipated. Under the Choucri and North hypothesis we expect negative coefficients; that is, multiplying a decrease in energy consumption by accompanying increases in population will result in a negative number. Except for democratic major powers, the effect of decreases in energy on dispute initiation is unmistakable. This begins in the third-year lag and persists across seven or eight years, but with decreasing size. What is interesting about these results is not that they appear so quickly-one would not reasonably think that they should take a long time to turn up since decreases in energy indicate problems that leaders are likely to address sooner rather than later-but that they persist so long and also occur in non democratic states, 
where leaders are not thought to respond as much as democratic leaders to the needs of the population. Table 2 displays the coefficients for the interaction of democratic minor powers and population growth and the interactions of democratic minor powers, population growth and energy consumption and that same interaction for the non democratic states. ${ }^{6}$

That said, there is a notable departure from this pattern of negative coefficients in the results shown for the interaction of the rate of population growth and changes in energy consumption. This variable captures this effect for the democratic major powers, and what it shows is that when both of these variables are increasing there is an unmistakable association with the initiation of disputes. This effect begins in the third lag and persists until lag for the seventh year. Recall that for these states neither population growth alone nor increases in energy consumption had discernible positive effects on dispute initiation. Together, however, they have a clear association with dispute initiation. What this may be capturing is the dynamics of vibrant economic growth being projected on the international environment as fueled by increases in both population and energy consumption. The individual coefficients for this relationship and their confidence intervals are shown in Table 2.

We now consider changes that might be present in the relationships of interest between the time periods 1816-1919 and 1920-1994. We do this for two related reasons. First, the number of minor power democratic states has not been constant. The number of democratic states increased sharply in the years following World War I. For example, in the year 1913 there are only 12 states in our data set (about 30 per cent of all the states) that qualify as democratic, and only nine of these are minor powers. However, by 1925 the number of democratic states had increased to 25 (42 per cent of the states), and 21 of these were minor powers. Second, because of the significant changes in the franchise made by many states after World War I, a number of those earlier classed as institutionally democratic effectively became "more democratic" as political participation increased sharply. Under that change in circumstances we might expect governments to be even more accommodating of the needs of the population. 


\section{Table 2 about here}

Accordingly, we divide the data into two periods at 1919-1920 and run the same model used to generate the results shown in Figure 1. The results appear in Figure 2 for the 18161919 period and Figure 3 for the 1920-1994 period, with those coefficients that did not include a zero in their confidence interval being shown in Tables 3 and 4, respectively. The results for the period prior to 1920 are relatively sparse in comparison to what was shown in Table 2. In the early period the coefficients for democratic major powers in the four and five-year lags, as shown in the population growth variable, are positive, and the confidence intervals do not include zero. Contrary to what was shown above, there is not much indication of a relationship between population growth and conflict for the other types of states. Only the coefficients for population growth in democratic minor power states has the predicted sign, but all the coefficients have confidence intervals that include zero. However, the interaction of changes in population and changes in energy consumption appears to contribute to dispute initiation for both types of minor powers and the non democratic major powers as well. Unlike the results for the full period reported above these effects appear later, beginning in the fifth-year lag, and last longer, stretching out to the tenth-year and eleventh-year lags. Table 3 shows the coefficients with confidence intervals that did not include zero. Once again, the combination of the growth in energy consumption and population growth for the democratic major powers appears to be linked to conflict initiation, beginning in the year five lag and continuing with a single break to the lag for the ninth year.

Figure 2 about here

Table 3 about here 
Figure 3 and Table 4 display and report the results for the period 1920-1994. As shown in the population growth variable, the effect of population growth alone is of little consequence for the democratic major powers. Neither is there much effect for population growth on dispute initiation for the non democratic major powers. However, beginning in the third-year lag and running out to the twelfth-year lag, democratic minor powers show an extended string of positive coefficients that do not include zero in the confidence intervals. The coefficients decrease across time, dropping from 0.79 in the third-year lag to about half that value by the sixth-year lag, as displayed in Table 4. No effect is shown in the results for the nondemocratic minor powers.

The variables that include energy consumption clearly show that for both democratic and non democratic minor powers the combination of increasing population and decreasing energy consumption had positive effects on conflict initiation. For the democratic minor powers this effect is manifest in the two-year lag and persists to the seventh-year lag, but again the size of the coefficients decreases quickly, losing more than half their original value between the two-year and three-year lags. The non democratic minor powers follow a similar pattern, but with smaller coefficients and a shorter period of clear association, running across the lags for only years three and four. The democratic major powers, once again, reveal a pattern in which the combination of population growth and increases in energy consumption are associated with conflict initiation. This begins in the lag for the third lag and continues to the seventh year.

\section{Figure 3 about here}

\section{Table 4 about here}

Thus far most of the results we have presented are broadly consistent with what we stated as our expectations, but there is one major exception to this. It may be useful to summarize what we expected to find and did and also discuss the notable exception. 
Following Tir and Diehl, except for two lags in the 1920-1994 period, the democratic major powers do not manifest results indicating that population pressure alone leads to dispute initiation. At the same time, the general manifestation of the effect of population growth can be seen in the democratic minor powers but not in their non-democratic counterparts. This is true over long lags in both the full analysis and in the period following 1919. Perhaps the most interesting results are those that report coefficients for the interactions of the types of states, population growth and energy consumption. Consistent with the ideas of Choucri and North, over the three to seven-year lags there is abundant evidence that when population is growing a decrease in energy consumption is associated with dispute initiation. This is the case for all the states except the democratic major powers over the entire period and the non-democratic major powers in the period 1920-1994.

There is, however, a pattern in our results we did not anticipate: the positive effect of the combination of population growth and increases in energy consumption on dispute initiation by the democratic major powers. It obtains in all three of the analyses, but is notably weaker in the period prior to 1920. If we are tempted to see the other results that include energy consumption as diversionary in their nature, what are we to make of this? We speculated earlier that this pattern in the data might be due to the dynamics of vibrant states. If so, then this vibrancy is limited to the democratic major powers because no such pattern is evident for the non democratic major powers. A more specific form of this speculation is that since the democratic major powers over this period were largely capitalistic, this pattern in the data is reflective of the "success" of their economic systems in overcoming economic difficulties even while population was growing. Another possibility is that the capitalist democracies were using their increased population and energy consumption to further imperialist policies to greater advantage than their non democratic, non capitalist rivals. Possibly so, but note that the pattern is weaker in the period before World War I when imperialist policies were more prevalent. At this point, what we can say with confidence is that we are puzzled. 
We noted above that the results for the coefficients containing the interaction for energy consumption were, except for the democratic major powers, consistent with the ideas of Choucri and North. There is, unfortunately, a problem with accepting this position with confidence, since the results are also consistent with the idea that when political leaders are confronted with domestic economic difficulties, which could readily be revealed by decreasing energy consumption, they will resort to generating political support through so-called rallyproducing activities. These might include initiating external conflicts. Note that while the results displayed in Figure 1 and reported in Table 2 appear in the lag for the third year, in the period 1920 to 1994, displayed in Figure 3 and reported in Table 4, they appear in the year-two lag. In both instances they appear quickly and dissipate almost as quickly. This suggests a process that is driven by something that is short-run, as in political difficulties, rather than long run, such as access to resources. This pattern in the data is suggestive of what is often termed the diversionary theory of war. This is the idea that when domestic political events are unsettling to the regime, leaders will seek to distract attention from these by engaging in conflict generating acts. ${ }^{7}$

One way of exploring the uncertainty of the results dealing with energy consumption is to consider the question of resource seeking. If the results are motivated by resource seeking, then we should expect to find a relationship between decreases in energy consumption and seeking resources through gaining territory. The COW data identify those disputes that are territorial in nature. Using the annual count of those for each state furnishes a new dependent variable to which our model may be applied. Since the counts in this variable are not as dispersed as the previous analyses we use a Poisson model for the analysis.

The results from this analysis, which we do not display, show an association between the initiation of disputes over territory and the interactions involving population growth and energy consumption only for democratic minor powers (-.08) and non democratic major powers (-.11), and these are observed only in the case of the year-four lag. All the rest of the coefficients have zero in their confidence intervals. This is far from strong support for the 
Choucri and North ideas. If the need for resources was driving conflict, we should expect it to be a more prolonged process. ${ }^{8}$

\section{Conclusion}

What are we to make of these results? On the positive side our expectations find broad support. Like Tir and Diehl, we can identify a process in which population growth has a palpable effect on a state's participation in and initiation of serious international conflict. However, going beyond their results the estimates in our analysis point to a conflict generating process that is not the property of minor powers generally, as shown by Tier and Diehl. Rather, it is minor powers with democratic political institutions, something that has not been identified before, as far as we are aware. That most of this effect is shown in the period after 1919 is also consistent with increasing numbers of democratic states and levels of participatory democracy in already institutionally democratic states. That the effects of population growth on conflict initiation in these states show up so quickly is perhaps a bit of a mixed tribute to the responsiveness of democratic institutions. Following Wright (1955) we believe the data lend support to the conclusion that population growth creates a "necessity for action," and this necessity is particularly strong among minor power democracies.

Moreover, when we combine population growth and changes in energy consumption there are, as shown and described above, palpable consequences for dispute initiation. We confess that our original reason for suspecting the possibility of such a relationship was the ideas of Choucri and North. However, while we can not completely dismiss the possibility of such a relationship, the fact that the combination of population growth and decreasing energy consumption does not appear to contribute to disputes over territory is perplexing. Given the rapidity which which this effect appears, it seems more reasonable to at least suspect that it may be generated by diversionary tactics on the part of leaders who face domestic political or economic difficulties. Insofar as we are aware, this is the first time that an empirical analysis covering this broad a range of states and this long a time period has 
produced results consistent with the diversionary theory of conflict.

Finally, to the extent that one can use this type of analysis to say something about policy, there are some grounds for concern in our results. At present, a number of states and international organizations are pursuing policies aimed at increasing the number of democratic states. All these states are in the class of minor powers, although perhaps in some cases they do not want to remain there, and most have relatively high rates of population growth. If these states can become democratic in proximate clusters, and if the primary result of the Democratic Peace continues to hold, then we may see a diminution of serious international conflict. However, if the state is democratic and in what might be termed a "bad" neighborhood, that is, contiguous to non democracies, then levels of conflict may rise. This is not to discourage the growth of democracy, but it is to say that there may be reasons to encourage democratizing minor powers to restrain population growth, a policy that may be desirable for other reasons as well. 


\section{Notes}

${ }^{1}$ This is only a brief summary of the full scope of Tir and Diehl's research. They not only looked at the effect of total population growth over a ten year period, but they examined, as well, the growth of urban population and the presence of both total population growth and urban population growth given conflict. That is, when there was a dispute, what was a state's past rate of growth for total population and urban population.

${ }^{2}$ Dependencies are a particularly severe problem in dyadic data. For an expository analysis of their pernicious effects in that type of data, see Ward, Siverson and Cao (2007).

${ }^{3}$ So far as we are aware, this problematic aspect of the COW capability data has not been reported previously.

${ }^{4}$ Iran in 1987 was the overachiever, with 23 violent disputes, all of which were level 4 . This was the height of the so-called Tanker War, which was part of the larger Iraq-Iran War, and involved Iranian attacks of a limited sort against ships registered under a variety of flags.

${ }^{5}$ We recognize there is a good deal of controversy on this point, but we find the position taken by Ray $(2003,2005)$ persuasive and have adopted it here. For a discussion of this issue, see the several papers in the special issue of Conflict Management and Peace Science (Kadera and Mitchell, 2005) on this subject.

${ }^{6}$ Because so many of the cases involve no conflict participation (see Table 1), we also used a hurdle model in which the first stage modeled dispute participation and the second the number of disputes. The results from these are not materially different across those we report here and below. We are grateful to Lanny Martin for suggesting this procedure.

${ }^{7}$ There is a moderately large literature on this. An excellent summary of the early literature is in Levy (1989). Exemplars of more recent empirical research on this topic may be found in Miller $(1995,1999)$ and Chiozza and Goemans (2003).

${ }^{8} \mathrm{In}$ an empirical paper of this sort, readers may be accustomed at this point to a presentation and discussion of marginal effects. Such an analysis is made problematic in this case by the many interaction terms in our model. The principal difficulty is that we cannot vary an interactive term without simultaneously varying the main effects. 


\section{References}

Bennett, D. Scott and Allan Stam. 2000. "Eugene: A conceptual manual." International Interactions, 26:179-204.

Bueno de Mesquita, Bruce, Alastair Smith, Randolph M. Siverson, and James D. Morrow. 2003. The Logic of Political Survival. MIT Press, Cambridge.

Cameron, A. Colin and Pravin K. Trevedi. 1998. Regression Analysis of Count Data. Cambridge University Press, New York.

Chiozza, Giacomo and H. Goemans. 2003. "Peace through insecurity: Tenure and international conflict." Journal of Conflict Resolution, 47:443-467.

Choucri, Nazli and Robert C. North. 1975. Nations in Conflict: National Growth and International Violence. W. H. Freeman and Co., San Francisco.

Choucri, Nazli, Robert North, and Susumu Yamakage.1992. The Challenge of Japan Before World War II and After: A Study of National Growth and Expansion. Routledge, London and New York.

Kadera, Kelly and Sara McLaughlin Mitchell. 2005. "Model specification and control variables." Special Issue of Conflict Management and Peace Science, 22(4):273-363.

Krebs, Ronald and Jack Levy. 2001. "Demographic change and the sources of international conflict." In M. Weiner and S. S. Russell, editors, Demography and National Security. Berghahn Books, New York.

Levy, Jack S. 1989. "The diversionary theory of war: A critique." In M. Midlarsky, editor, The Handbook of War Studies, pages 259-88. University of Michigan Press, Ann Arbor.

Lieberson, Stanley. Making it Count: The Improvement of Social Research and Theory.Berkeley: The University of California Press. 
Miller, Ross A. 1995. "Domestic structures and the diversionary use of force." American Journal of Political Science, 39:760-85.

Miller, Ross A. 1999. "Regime type, strategic interaction, and the diversionary use of force." Journal of Conflict Resolution, 43(3):338-402.

Organski, A.F.K. and Jack Kugler. 1980. The War Ledger University of Chicago Press, Chicago.

Ray, James Lee. 2003. "Explaining interstate conflict and war: What should we control for?" Conflict Management and Peace Science, 10:1-31.

Ray, James Lee. 2005. "Constructing multivariate analyses (of dangerous dyads)." Conflict Management and Peace Science, 22:277-292.

Small, Melvin and J. David Singer. 1982. Resort to Arms. SAGE Publications, Beverly Hills.

Tir, Jaroslav and Paul F. Diehl. 1998. "Demographic pressure and interstate conflict: Liking population growth and density to militarized disputes and wars, 1930-89." The Journal of Peace Research, 35(3):319-339.

Ward, Michael D., Randolph M. Siverson, and Xun Cao. 2007. "Disputes, democracies, \& dependencies: A re-examination of the kantian peace." American Journal of Political Science.

Wintrobe, Ronald. 1998. The Political Economy of Dictatorship. New York: Cambridge University Press.

Wright, Quincy. 1955. The Study of International Relations. Appleton Century Crofts, New York. 


\begin{tabular}{lccc}
\hline \hline N. Inits. & Freq. & Percent & Cum. \\
\hline \hline 0 & 6,828 & 84.77 & 84.77 \\
1 & 882 & 10.95 & 95.72 \\
2 & 228 & 2.83 & 98.55 \\
3 & 71 & 0.88 & 99.43 \\
4 & 16 & 0.20 & 99.63 \\
5 & 11 & 0.14 & 99.76 \\
6 & 7 & 0.09 & 99.85 \\
7 & 2 & 0.02 & 99.88 \\
8 & 1 & 0.01 & 99.89 \\
9 & 2 & 0.02 & 99.91 \\
10 & 2 & 0.02 & 99.94 \\
11 & 1 & 0.01 & 99.95 \\
14 & 2 & 0.02 & 99.98 \\
15 & 1 & 0.01 & 99.99 \\
23 & 1 & 0.01 & 100.00 \\
\hline \hline
\end{tabular}

Table 1: Annual Number of Militarized Interstate Disputes at Hostility Levels 3, 4, and 5. The N. Inits column lists the number of militarized interstate disputes in a country-year. The frequency column shows the number of states which had a given number of militarized disputes in a year. The per cent and cumulative columns show the dispute number as a percentage of a whole and as a percentage below a given dispute count, respectively. 


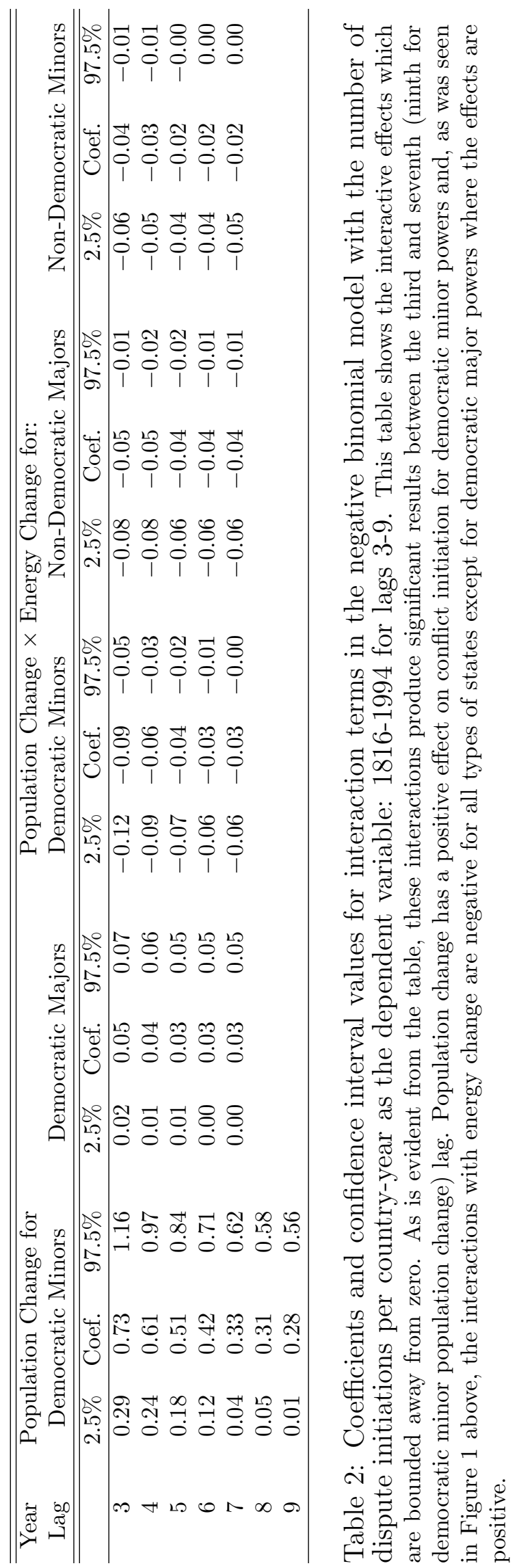




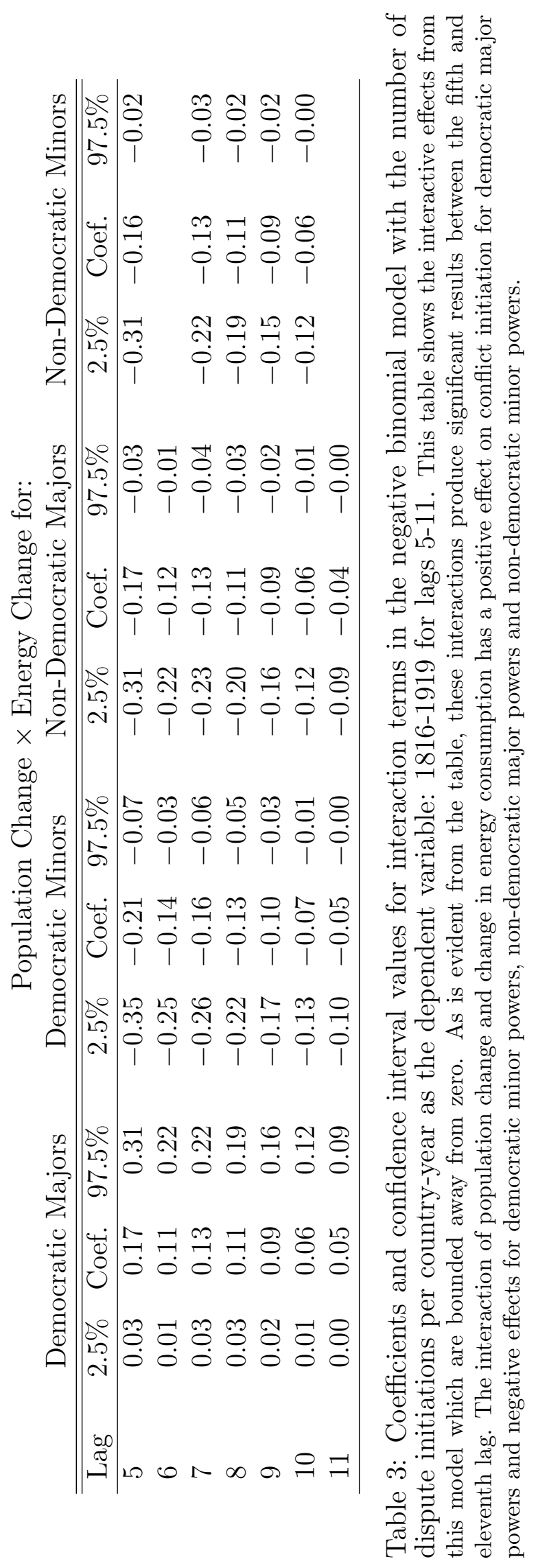




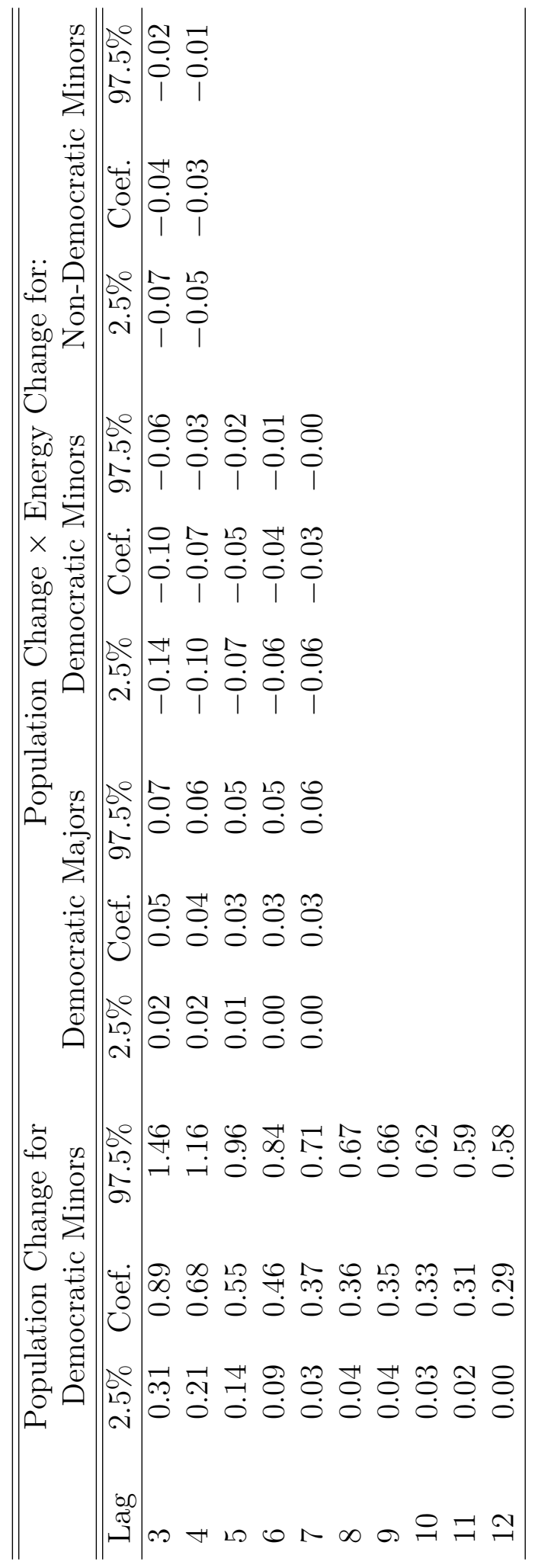

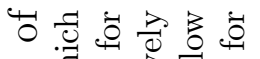

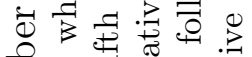

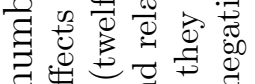

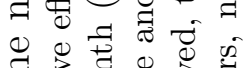

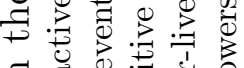

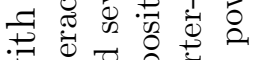

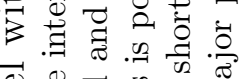

D

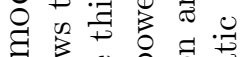

व

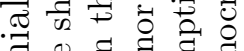

द्वृ

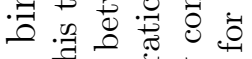

ए $\mathrm{F}$ की .

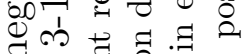

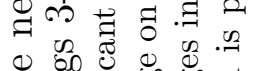
元 . $\approx$ 氙

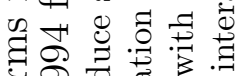

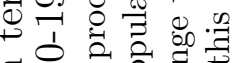

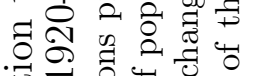

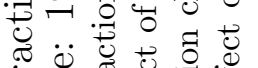

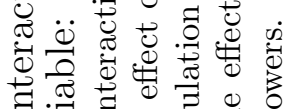

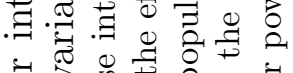

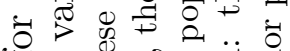

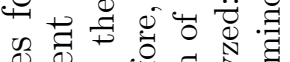

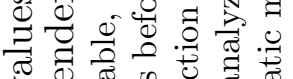

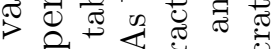
तं ¿

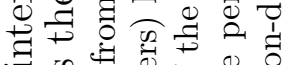

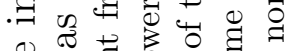

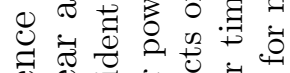
式

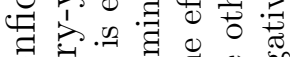

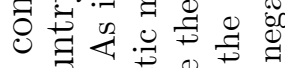
चี के

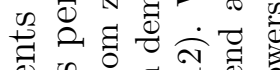

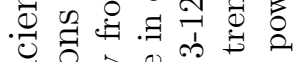

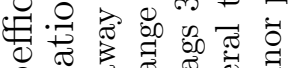
O.

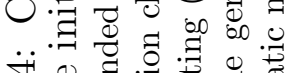
0

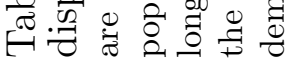



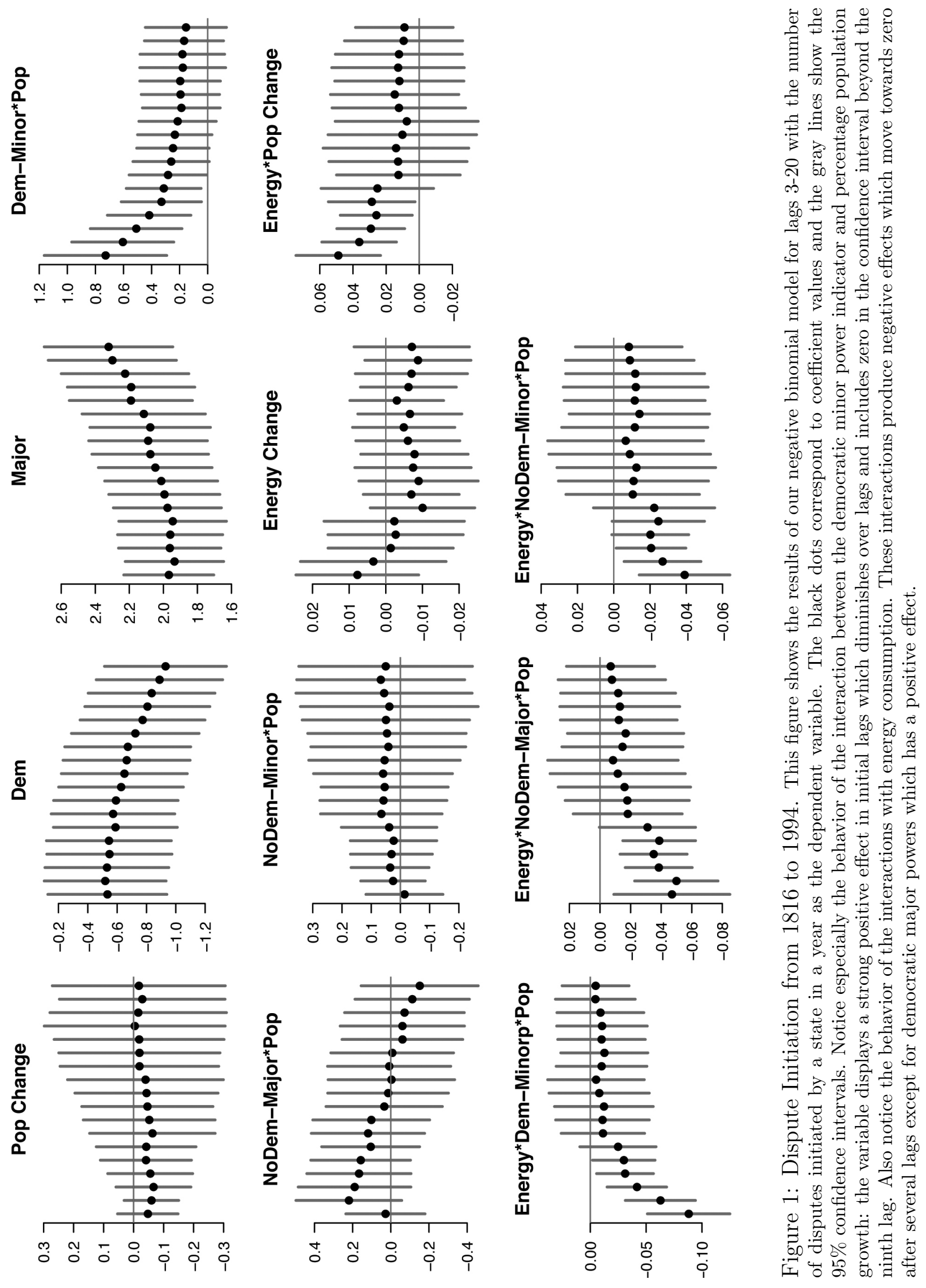

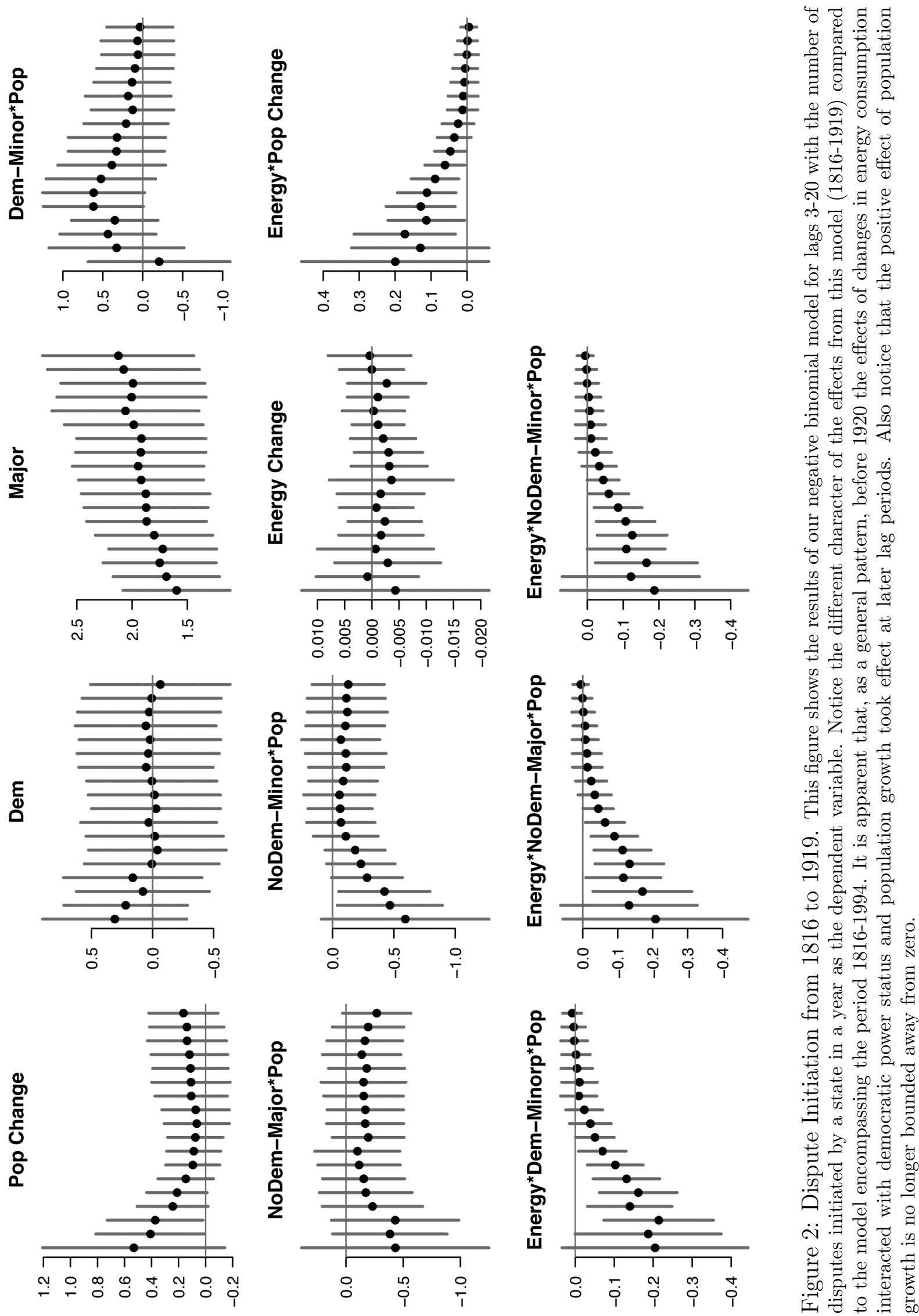

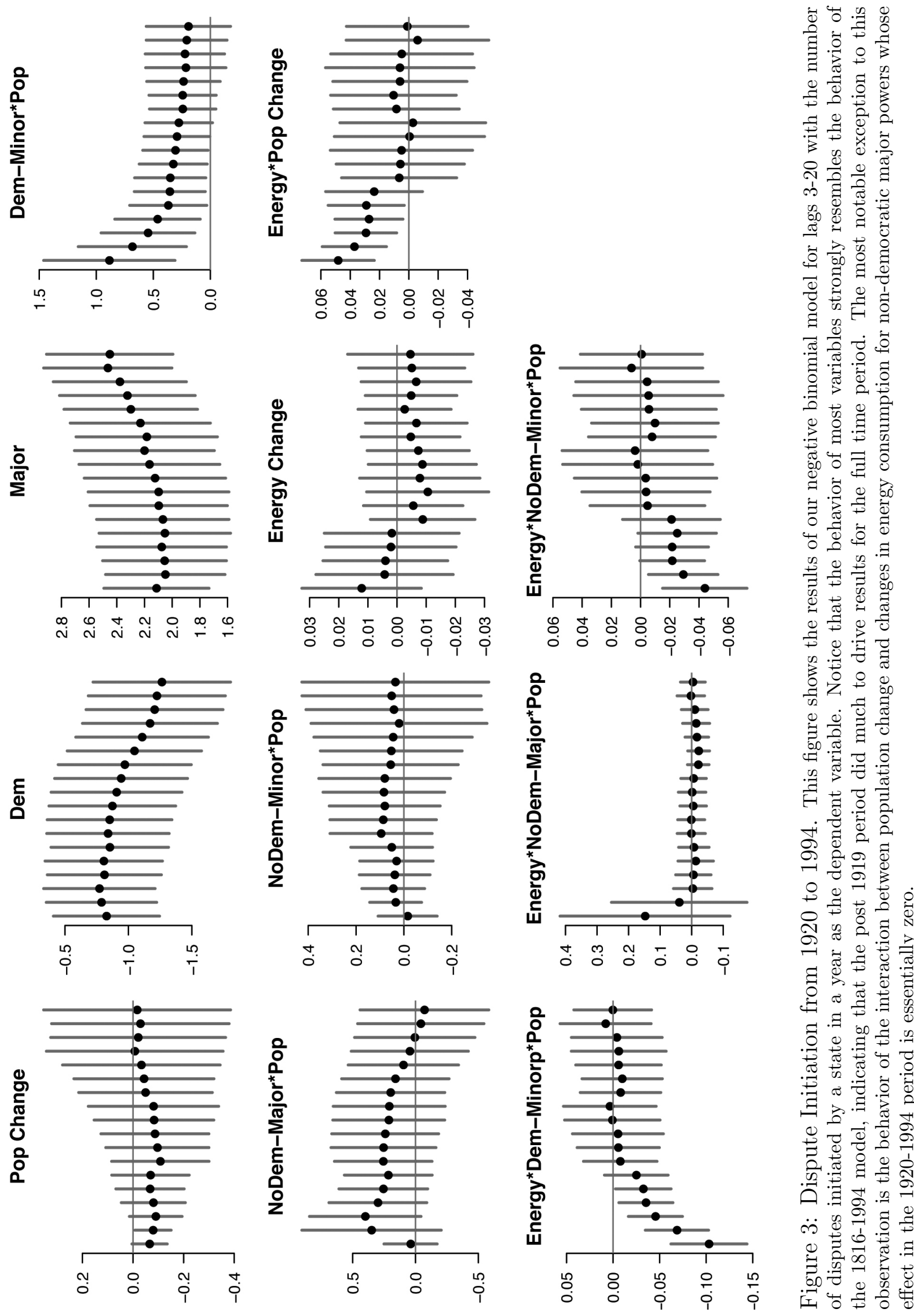